\title{
Notas para uma reflexão sobre a produção de tutelas jurídicas
}

\author{
Manoel Eduardo Alves Camargo e Gomes*
}

Sumário: Introdução; 1.Demandas sociais e tutela jurídica; 2.Diferenciação das demandas sociais; 3.Produção de tutelas jurídicas; 4.Considerações finais.

\section{Resumo}

O presente artigo, tendo um caráter preliminar, limita-se à formulação de alguns argumentos sobre o processo de formação das tutelas jurídico-políticas estatais, os quais apontam para a presença de uma conflitualidade e complexidade, indicativas de uma processualidade dialética e, até certo ponto, dialógicas, negadas pela doutrina tradicional. Estas indicações têm com suporte o entrechoque de diferentes demandas na constituição do aparato tutelar do Estado, as quais apresentam diferentes níveis de adequabilidade informados pela racionalidade do ordenamento jurídico em particular e do Estado em geral.

\section{Introdução}

Como uma demanda social emergente, contrária aos interesses de setores sociais hegemônicos, é recepcionada pelo sistema jurídico, recebendo o status de bem ou atividade juridicamente tutelada pelo Estado?

Não obstante sua aparente simplicidade, esta questão repercute diretamente sob o nível de 'egitimação do direito e de governabilidade do Estado. Ali, por interrogar acerca dos sujeitos e interesses envolvidos no

* Advogado, Professor da UFPR, Mestre em Instituições Jurídico-Políticas (UFSC/SC), Doutorando em Direito do Estado (UFSC/SC).

R. Fac. Direito, Curitiba, a.28, n.28, 1994/95, p.97-107 
processo de formação do direito. Aqui, por questionar a seletividade vigente no processo de recepção de bens e interesses tutelados pelo Estado.

A questão situa-se no âmbito da formação do direito: um locus teórico esterilizado pela doutrina tradicional que, utilizando-se de uma consensualidade tão imaginária quanto desprovida de suporte empírico, torna impessoal e homogêneo o processo de formação do direito.

Parece, pois, necessário, mais do que fornecer respostas, produzir indagações que desvelem a complexidade e a conflitualidade não só ínsitas como decisivas no processo de formação do direito, negadas pela doutrina tradicional.

Para tanto, ultrapassando os estreitos limites da causalidade unilinear, este texto procura demonstrar a presença de uma processualidade dialética e, até certo ponto, dialógica, na produção do direito contemporâneo, fatores constituintes da realidade empírica.

\section{Demandas sociais e tutela jurídica}

A reflexão sobre o processo de inclusão de demandas sociais contrárias aos interesses hegemônicos no âmbito das tutelas jurídicas. não se deve limitar ao campo de discussão que se desenvolve acerca dos direitos de minorias.

Ao menos para as nascentes democracias periféricas a questão é mais complexa: a arquitetura institucional do setor público e os procedimentos jurídico-administrativos de inclusão de demandas sociais foram concebidos em conjunturas políticas pouco democráticas e, no mais das vezes, informadas por estratégia de exclusão de demandas majoritárias.

As próprias cartas constitucionais dos Estados periféricos revelam desde logo tal distorção, demonstrada pelo déficit de instrumentos jurídicos de formulação de políticas públicas e de produção normativa, de um lado e pela superlatividade de instrumentos de controle dé ações públicas, de outro.

É evidente que esse estrangulamento dos canais institucionais de acesso à formação de políticas públicas e produção normativa, conjugado com um arsenal tão técnico quanto oneroso de instrumentos jurídicos 
garantidores de direitos individuais, acaba por privilegiar direitos de minorias, não étnicas nem políticas, mas econômicas. ${ }^{1}$

Assim. nos Estados periféricos, as demandas sociais provindas de outras minorias (não econômicas) e mesmo as de setores majoritários da população, para além da necessidade de adquirirem habilidade frente aos processos seletivos, enfrentam o fato de que a mecânica de seleção é informada por uma racionalidade típica, no mais das vezes incompatível com tais demandas.

Em termos práticos: em um dado município, a demanda para a inclusão de mecanismos públicos que auxiliem e subvencionem a iniciativa de um grupo de empresários que desejam implantar uma grande empresa, é muito mais facilmente absorvível pelo Poder Público Municipal (na forma de incentivos fiscais, qualificação de mão-de-obra, construção de infraestrutura etc.), do que a demanda de um grupo ambientalista, por exemplo, para que sejam fixados procedimentos de tratamento dos resíduos poluidores dessa mesma empresa.

Cuida-se de demandas com diferentes níveis de compatibilidade com a racionalidade vigente. Isto importa em estratégias de inclusão diferenciadas, fato dificilmente admitido em face da pretensão "universalista" (sic) dos procedimentos jurídico-administrativos dos Estados de Direito na contemporaneidade. $^{2}$

1 Aliás, essas, historicamente, têm apresentado crescente habilidade frente ao processo seletivo de inclusão de suas demandas e domínio na instrumentalização dos mecanismos jurídicos de controle do Estado.

2 Não se quer, com isto, abrandar a necessidade de se habilitar politicamente os atores sociais frente aos processos seletivos de filtragem presentes no âmbito da formulação de políticas públicas e na produção normativa nem, tampouco, reduzir a importância de uma aprendizagem voltada pąra o domínio dos instrumentos jurídicos de controle das ações públicas prejudiciais aos interesses coletivos. O que se pretende é aumentar o potencial de factibilização de ambas as necessidades, por meio de uma reflexão que parta da constatação de uma diferença ínsita às demandas sociais que são apresentadas ao Estado.

R. Fac. Direito, Curitiba, a.28, n.28, 1994/95, p.97-107 


\section{Diferenciação das demandas sociais}

A inteligibilidade deste complexo processo de recepção de bens e atividades pelo sistema jurídico passa, primeiramente, pela diferenciação das demandas que lhe são subjacentes.

O cenário contemporâneo tem estampado com muita clareza que as demandas populares, situando-se, pois, fora dos campos de poder dos setores hegemônicos, na clássica visão do marxismo que concebe o Estado como "instrumento" das classes dominantes, ${ }^{3}$ jamais obteriam a requerida tutela político-jurídica do Estado.

A compreensão do processo de inclusão destas demandas no âmbito das políticas públicas, e mesmo do ordenamento jurídico estatal, requer o enfrentamento de uma complexidade inatingível por aquela tradicional concepção de Estado como "instrumento" da classe detentora dos meios de produção.

Segundo Offe, o conceito de Estado capitalista refere-se a uma forma institucional caracterizada, fundamentalmente, por quatro determinações: a) privatização da produção "o poder público está estruturalmente impedido de organizar a produção material segundo seus próprios critérios públi$\cos ^{\prime \prime} ; 4$ b) dependência dos impostos "o poder público depende, indire-

3 Ao menos até o desenvolvimento teórico de Poulantzas, que indo além de Althusser, sustentou que "O Estado nem está a serviço nem é 'instrumento' de uma classe contra outra. Sua estrutura e atividade consistem na imposição e na garantia duradoura de regras que institucionalizam as relações de classe específicas de uma sociedade capitalista. $O$ Estado não defende os interesses de uma classe, mas sim os interesses comuns de todos os membros de uma sociedade capitalista de classes." (Martin Carnoy, Estado e Teoria Politica, Trad. Equipe de redação da PUCCAMP, Campinas: Papirus Livraria e Editora, 1986, p. 163).

4 Offe fundamenta esta noção afirmando: "O fato de que uma parte substantiva do estoque de capital constitui propriedade do Estado, em algumas das sociedades industriais capitalistas desenvolvidas, só aparentemente contradiz essa afirmação. Pois inicialmente seria de perguntar se esta propriedade pública de meios de produção conduz a estratégia de utilização e aplicação diferentes das adotadas pelo capital privado. Se for esse o caso, impõe-se a pergunda adicional sobre se essa produção nolítica persegue outros objetivos que não os de pôr à disposição do processo de produção privada, de forma permanente e com baixos custos, bens infra-estruturais como eletricidade, transportes, etc." (Claus Offe, Problemas Estruturais do Estado Capitalista, Trad. Barbara Freitag, Rio de Janeiro: Ed. Tempo Brasileiro Ltda., 1984, p. 123). 
tamente, através de mecanismos do sistema tributário, do volume da acumulação privada"; ${ }^{5}$ c) acumulação como ponto de referência "como o poder estatal depende do processo de acumulação capitalista, sem ser ele mesmo capaz de organizar este processo, o interesse supremo e mais geral dos detentores do poder do Estado consiste em manter as condições de exteriorização de seu poder através da constituição de condições políticas que favoreçam o processo privado de acumulação"; e, d) legitimação democrática "sob as condições do sistema de governo parlamentar-democrático, um agrupamento ou um partido político só consegue se apropriar do poder estatal quando encontra o apoio majoritário". 7

Neste contexto teórico, Offe conclui que:

"O Estado capitalista está sujeito a uma dupla determinação do poder político-segundo sua Forma institucional, este poder é determinado pelas regras do governo democrático representativo; segundo o seu Conteúdo, é determinado pelo desenvolvimento e pelos requisitos do processo de acumulação". 8

Hisrch, adotando semelhante posição, entende que a forma histórica do Estado Contemporâneo é composta pelos seguintes elementos:

"...os obstáculos formais que impedem os portadores imediatos do poder estatal de "dispor" sobre os meios de produção; a alimentação do aparelho estatal a partir dos descontos na renda (Estado de impostos); a fragmentação das esferas do direito "privado" e "público"; o surgimento do funcionário profissional, do político profissional e, deste modo, da não-identidade formal da posição administrativa e da pertença a classes; finalmente, o desenvolvimento do sistema representativo parlamentar como esfera mediadora entre o aparelho estatal, aparelho de força e a sociedade civil". 9

5 Neste passo, Offe afirma que todo "detentor de posições de poder num Estado capitalista seria efetivamente por completo despojado do seu poder se um certo volume de acumulação e de ingressos [...] não lhe permitisse manifestar o seu poder também com meios materiais" (op. cit. p.124).

6 Offe, Problemas..., op. cit., p. 124.

7 Offe, Problemas..., op. cit., p. 125.

8 Id. Ibidem, A respeito ver Manuel Eduardo Alves Camargo Gomes, "Participação popular no controle ambiental", Revista de Informação Legislativa, Brasília, Senado Federal (104) 331-336, out./dez. 1989, p. 232.

9 Joachim Hirsch, et. alii., A Teoria do Estado, Trad. Flávio Beno Siebeneichler, Rio de Janeiro, Ed. Tempo Brasileiro, 1990. p. 150.

R. Fac. Direito, Curitiba, a.28, n.28, 1994/95, p.97-107 
Para Hirsch, o arranjo desses elementos na composição da forma estatal "... implica que a determinação estatal da função de garantia das condições gerais de reprodução do capital tem de colidir permanentemente com os interesses de capitais particulares e de grupos de capital e com o interesse emancipatório da classe dos trabalhadores em geral". ${ }^{10}$

Macpherson, valendo-se das contribuições da teoria marxista, reconhece este permanente confronto no interior do Estado:

"Mas agora o poder do Estado depende da continuidade da acumulação capitalista. E como agora o Estado é democrático, ele enfrenta duas novas dificuldades: tem de conciliar as exigências da acumulação com as reivindicações do eleitorado, e tem de extrair do capital uma receita cada vez maior para poder financiar seu apoio ao capital e também ao eleitorado". ${ }^{11}$

Essas contribuições são suficientes para indicar que a entronização de bens e atividades no raio tutelar do ordenamento jurídico se processa a partir do entrechoque entre (1) as demandas voltadas a aumentar a legitimação política do Estado e (2) as dirigidas à reprodução da acumulação capitalista, às quais são mediadas por (3) uma estrutura estatal relativamente autônoma. Em outras palavras, entram em conflito as demandas populares que mais diretamente afetam o potencial de legitimação do Poder Público, as voltadas para a reprodução do processo da acumulação capitalista e as do próprio Estado, também de uma demanda relativamente autônoma em relação às demais.

É a partir do impacto entre estas três demandas que os diferentes bens e atividades são entronizados, processados e apropriados pelo Estado na forma de auto-interesse institucional - instância última da produção e dos resultados da tutela estatal.

C. B. Macpherson, Ascensão e Queda da Justiça Econômica e Outros Ensaios. Trad. Luiz Alberto Monjardim, Rio de Janeiro, Ed. Paz e Terra, 1991, p. 94. 


\section{Produção de tutelas jurídicas}

Assim, ainda que em apressada sintese, poder-se-ia dizer que as diferentes demandas produzidas socialmente, para serem recepcionadas no âmbito das políticas públicas ou do ordenamento jurídico estatal, teriam que consubstanciar uma das seguintes situações: a) representar uma imediata e substancial vantagem para a expansão da acumulação privada; b) apresentar um ganho relevante na minimização do déficit de legitimação política do Estado; c) atender importantes interesses corporativos da burocracia estatal; d) ou ainda, não possuindo esta requerida importância em uma destas opções, apresentar uma razoável vantagem, concomitante ou alternativamente, no âmbito das três situações.

Considerando (1) a localização das demandas populares (como as ambientais, as de melhoria da habitação, transporte, saúde, saneamento básico, educação, condições salariais etc.), fora do campo de poder das elites econômicas e políticas, e (2) o baixo nível de compatibilização com a racionalidade em vigor, passa a ser virtual, ao menos ordinariamente, que a inclusão destas demandas passa pelo processo de legitimação política.

Fundamentalmente, a qualificação de uma demanda como representativa do ponto de vista de seu potencial de legitimação depende: a) da adequação da demanda à estrutura jurídica que fixa e regulamenta bens e atividades tuteladas pelo Estado; b) da oportunidade da demanda em vista da conjuntura política; c) do grau de mobilização e pressão subjacente à demanda sobre a conjuntura política e sua conformação; e, d) da resolubilidade ex ante da conjuntura política sobre a estrutura jurídica e, ex post desta sobre aquela.

Assim, o primeiro passo no sentido de qualificar uma demanda é auscultar sua plausibilidade objetiva (do ponto de vista conjuntural e estrutural) no interior do sistema jurídico e político da sociedade no qual pretende ser recepcionada.

A análise desta ’̉ausibilidade não deve estar adstrita apenas à configuração interna da prática social que se pretende institucionalizar, 
mas também, e principalmente, ao delineamento e à conjuntura do sistema político e jurídico da sociedade. ${ }^{12}$

Caricaturando, dir-se-ia que não basta a defesa destas demandas por suas internalidades e externalidades positivas, tal como não tem sido suficiente a defesa de prática sociais como aborto e pena de morte por suas supostas vantagens na realidade empírica. ${ }^{13}$ É necessário levar em conta a configuração do sistema jurídico e político, o qual pode rechaçá-la ou recepcioná-la, de acordo com as objetivas condições definidas a priori ou ex ante.

Esta avaliação deve pressupor: (1) a existência de um modelo objetivamente definido da prática social que se pretende incluir no âmbito tutelar do Poder Público e (2) a apropriação cognitiva do sistema jurídico e político $^{14}$ do Estado.

Assim, a questão da adequabilidade passa para um outro nível. Do ponto de vista conjuntural, cuida-se da instrumentalização de algumas variáveis controláveis e inúmeras variáveis incontroláveis. Do ponto de vista estrutural, inversamente, da operacionalização de uma concepção estratégica que, considerando o alto nível de invariância, viabilize a inclusão de um modelo concebido em vista de uma necessária adequabilidade aferida a priori.

Em termos práticos, deve-se conjugar (1) elevação do nível de mobilização e pressão (oportunizando a conjuntura política) e (2) estruturação

12 "Alain Touraine e muitos autores frisam que nem toda carência transforma-se mecanicamente em reivindicação, pois nem toda representação sobre necessidade diluída ou mesmo expressa junto ao tecido social é reconhecida institucionalmente como demanda, seja pelo Estado, seja pelos organismos políticos tradicionais. Entre elas há um movimento de construção coletiva que depende da medição do direito, socialmente autorizado e normatizado por ambos os pólos da relação Estado-sociedade civil." (Apud Daniel Joseph Hogan (org.), Dilemas Socioambientais e Desenvolvimento Sustentável Campinas, SP, Ed. da Unicamp, 1992, p. 17).

13 Em que pese o autor deste projeto absolutamente não concordar com as ditas vantagens sociais do aborto e da pena de morte, o exemplo é válido para demostrar que estas são auto-referidas, sem qualquer consideração ao fato de a estrutura institucional, tendo-as como práticas ilícitas, estruturalmente abominá-las.

14 Note-se que a própria conjuntura é também conformada pela integralização do processo de qualificação da demanda. 
de um modelo institucional objetivo que, construído a partir do estudo de seu potencial de compatibilização à realidade empírica e à realidade jurídica, seja ao menos constitucionalmente adequável ao ordenamento jurídico.

Desta forma viabiliza-se uma substancial elevação do custo de legitimação estatal, oportunizando-se a inclusão. Para utilizar uma categoria de Bourdieu, ${ }^{15}$ poder-se-ia dizer que neste momento de "demanda sem efeito", o reclamo social começa a constituir uma "demanda com efeito", apresentando condições objetivas de plausibilidade, do ponto de vista de sua entronização no sistema jurídico.

Note-se que se trata de favorecimento de conjuntura e não de determinante conjuntural. Em outras palavras, se a bandeira de um modelo institucional objetivo adequável à estrutura jurídica é importante, não é por si só capaz de determinar qualquer inclusão.

Aqui parece legítimo indagar: sem um modelo desta natureza seria possível falar em inclusão? Possivelmente sim, em conjunturas políticas altamente favoráveis como ocorreu em alguns momentos do processo constituinte brasileiro de 1988 .

Não obstante, convém ressaltar que qualquer forma de modelo legal tem de ser constituído, se não pelo próprios protagonistas da demanda, pelos agentes do Estado, o que elevaria o risco de distorção da proposta original. Deve-se considerar ainda que a ausência de um modelo capaz de ser prontamente recepcionado pode retardar seu processo de institucionalização no sistema jurídico, com elevados riscos de desfavorecimento da conjuntura política. Cabe também atentar que a própria pressão e mobilização subjacente às demandas populares perdem força e resolutividade na ausência de modelos objetivos, à medida que se estabelece uma relação dialógica entre mobilização e consubstanciação de um objetivo nucleado a partir de uma proposta unificada. Por fim, diga-se que, em se tratando de institucionalização de questões específicas, a força da pressão sobre o acervo de legitimação do Pcłer Público decresce em razão direta de sua abstração e difusão. 


\section{Consideração finais}

Estas indicações, vez que sem substrato experimental, evidentemente, são precárias. No seu conjunto, apontam para a necessidade de um aprofundamento não só teórico, como empírico, para um campo de reflexão que se situa aquém da legalidade: a mais cara conquista da democracia e do Estado de Direito.

Diversos estudos foram realizados no sentido de garantir sua vigência, entretanto, a maior parte de uma legalidade já instituída, sem o aprofundamento do processo que a institui.

Frente a constante e veloz mutabilidade do cenário jurídico-político contemporâneo, parece fundamental uma permanente reflexão sobre os canais e os procedimentos institucionais de produção normativa, vez que é também neste âmbito que se assegura ao direito sua eficácia social.

Ainda que se reconheça toda a importância, os estudos voltados para a modernização da prestação jurisdicional, é também neste campo de produção normativa, muito anterior à aplicação do direito, que o sentido de justiça começa a ser fixado.

Nesta medida, este artigo teve como objetivo salientar a possibilidade de uma reflexão sobre o processo de formação do direito que, partindo de uma complexidade e conflitualidade não admitidas pela doutrina tradicional, reconheça uma processualidade dialética, e até certo ponto dialógica, na produção normativa do Estado.

Para atingir este objetivo, procurou-se demostrar (1) o entrechoque de diferentes demandas na constituição do aparato tutelar do Estado, as quais apresentam (2) diferentes níveis de adequabilidade informados pela racionalidade do ordenamento jurídico em particular e do Estado em geral, o que torna aconselhável a (3) operacionalização de comportamentos estratégicos diferenciados, no processo de formação das tutelas jurídicas estatais.

A percepção e aprofundamento destas diferenças presentes no processo de formação do direito devem favorecer uma rediscussão, não só acerca dos limites fixados pela doutrina tradicional ao tema, como também dos atuais parâmetros de avaliação do déficit de legitimação que atinge o direito contemporâneo. 


\section{Referências Bibliográficas}

BOURDIEU, Pierre. Sociologia. São Paulo: Ed. Ática. 1983.

CARNOY, Martin. Estado e Teoria Política. Trad. Equipe de redação da PUCCAMP. Campinas: Papirus Livraria e Editora. 1986.

GOMES, Manoel Eduardo Alves Camargo e. "Participação popular no controle ambiental." Revista de Informação Legislativa. Brasilia: Editora do Senado Federal. (104): 331-336, out./dez. 1989.

HIRSCH. Joaquim, et. alli. A Teoria do Estado. Trad. Flávio Beno Siebeneichler. Rio de Janeiro: Editora Tempo Brasileiro, 1990).

HOGAN. D. J. (org.). Dilemas socioambientais e desenvolvimento sustentável. Campinas: Ed. da Unicamp. 1992.

MACPHERSON, C.B. Ascensão e queda da justiça econômica e outros ensaios. Trad. Luiz Alberto Monjardim. Rio de Janeiro: Ed. Paz e Terra. 1991.

OFFE. Claus. Problemas estruturais do Estado Capitalista. Trad. Bárbara Freitag. Rio de Janeiro: Ed. Tempo Brasileiro Ltda.. 1984, 386p.

R. Fac. Direito, Curitiba, a.28, n.28, 1994/95, p.97-107 